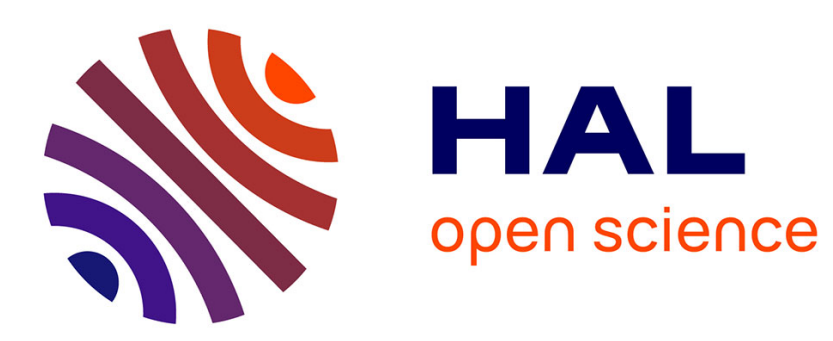

\title{
On the pressure dependence of a charge density wave state in $2 \mathrm{H}$-Tas 2
}

R. Delaplace, Ph. Molinie, D. Jerome

\section{To cite this version:}

R. Delaplace, Ph. Molinie, D. Jerome. On the pressure dependence of a charge density wave state in 2H-Tas 2. Journal de Physique Lettres, 1976, 37 (1), pp.13-15. 10.1051/jphyslet:0197600370101300 . jpa-00231219

\section{HAL Id: jpa-00231219 https://hal.science/jpa-00231219}

Submitted on 1 Jan 1976

HAL is a multi-disciplinary open access archive for the deposit and dissemination of scientific research documents, whether they are published or not. The documents may come from teaching and research institutions in France or abroad, or from public or private research centers.
L'archive ouverte pluridisciplinaire HAL, est destinée au dépôt et à la diffusion de documents scientifiques de niveau recherche, publiés ou non, émanant des établissements d'enseignement et de recherche français ou étrangers, des laboratoires publics ou privés. 


\title{
ON THE PRESSURE DEPENDENCE OF A CHARGE DENSITY WAVE STATE
} IN $2 \mathrm{H}-\mathrm{TaS}_{2}(*)$

\author{
R. DELAPLACE, Ph. MOLINIE (**) and D. JEROME \\ Laboratoire de Physique des Solides (***), Université Paris-Sud, 91405 Orsay, France
}

(Reçu le 1er octobre 1975, accepté le 27 octobre 1975)

Résumé. - Nous présentons une étude sous pression jusqu'à 33 kbar de la température d'apparition de l'onde de densité de charger $T_{\mathrm{CDW}}$ dans le polytype $2 \mathrm{H}-\mathrm{TaS}_{2}$. Le coefficient de pression vaut

$$
\frac{\partial \ln T_{\mathrm{CDW}}}{\partial P}=2,9 \times 10^{-3} \mathrm{kbar}^{-1}
$$

à la pression atmosphérique. La dépendance en pression de $T_{\mathrm{CDw}}$ indique que l'état métallique normal de $2 \mathrm{H}-\mathrm{TaS}_{2}$ devrait être stable à basse température à des pressions supérieures à $43 \mathrm{kbar}$. Nous discutons brièvement la relation possible entre l'onde de densité de charge et l'augmentation de la température supraconductive sous pression.

Abstract. - The onset of a charge density wave has been studied by resistivity measurements in $2 \mathrm{H}-\mathrm{TaS}_{2}$ up to $33 \mathrm{kbar}$. The pressure coefficient of $T_{\mathrm{CDW}}$ is

$$
\frac{\partial \ln T_{\mathrm{CDW}}}{\partial P}=2.9 \times 10^{-3} \mathrm{kbar}^{-1}
$$

at ambient pressure. A larger pressure dependence occurs at higher pressure and suggests that the normal metallic state of $2 \mathrm{H}-\mathrm{TaS}_{2}$ may be stable down to $0 \mathrm{~K}$ above $43 \mathrm{kbar}$. The relation between a CDW state and the pressure enhanced superconductivity is discussed.

It has been recognized recently that layer compounds such as the hexagonal dichalcogenides are good candidates for the observation of charge density waves (CDW) [1, 2, 3]. The reason lies in the 2-dimensional character of the Fermi surface of these materials which exhibits cylindrical regions along the $\Gamma A$ axis. This fact favours a good nesting over large areas of the Fermi surface and causes enhanced Kohn anomalies in the phonon spectrum for those wave vectors corresponding to the spanning vectors. At low temperature, these Kohn anomalies condense into static distortions which have been observed recently by electron diffraction techniques in the $1 \mathrm{~T}$ polytypes of $\mathrm{TaS}_{2}$ or $\mathrm{TaSe}_{2}[1,4]$. Additional experimental evidence for the intrapolytypic phase transition has been obtained from resistivity, susceptibility [3] and neutron diffraction data [3].

The clearest evidence for the existence of a CDW coupled to a periodic lattice distortion comes from the

$\left({ }^{*}\right)$ This work has been supported in part by the D.G.R.S.T., contract $\mathrm{n}^{\circ} 7470877$.

$(* *)$ Permanent address : Laboratoire de Chimie Minérale A BP 1044, Nantes, France.

${ }^{(* * *)}$ Laboratoire associé au C.N.R.S. extra reflections occurring around the Bragg reflections of the undistorted lattice on the electron diffraction patterns. The periodic distortion is incommensurate with the primitive lattice below the onset temperature.

A locking to a commensurate periodic distortion may occur on further cooling [5].

The onset of a CDW state introduces gaps in the energy spectrum in some selected directions on the Fermi surface. Therefore, a metal-insulator transition is observed for the 1T polytypes which have simpler Fermi surface shapes. For the $2 \mathrm{H}$ polytypes, the trigonal prismatic coordination of metal atoms leads to a two sheeted Fermi surface and to the occurrence of a metal-metal transition at the onset of a CDW state.

Neutron scattering studies have revealed the onset of incommensurate CDW at $T_{0}=33.5 \mathrm{~K}$ in $2 \mathrm{H}-\mathrm{NbSe}_{2}$ and at $T_{0}=122.3 \mathrm{~K}$ in $2 \mathrm{H}-\mathrm{TaSe}_{2}$ [5].

In $2 \mathrm{H}-\mathrm{TaSe}_{2}$, resistivity studies have revealed a sharp anomaly at $75.3 \mathrm{~K}[6,7]$ and electron diffraction patterns exhibit weak extra reflections at $66 \mathrm{~K}$ corresponding to a superlattice parameter $\simeq 0.3 a^{*}$ and diffuse streaks linking the main Bragg spots at room temperature. 
It has been pointed out that the $2-d$ character of the band structure is very sensitive to the interlayer separation [8]. The application of a hydrostatic pressure modifies preferentially the $c$-axis parameter $[9,10]$.

In this note, we report a study of $2 \mathrm{H}-\mathrm{TaS}_{2}$ at high hydrostatic pressures up to $33 \mathrm{kbar}$ and between 300 and $4.2 \mathrm{~K}$ by resistivity measurements.

The synthesis of $2 \mathrm{H}-\mathrm{TaS}_{2}$ single crystals was performed using a transport method under iodine pressure. Stoichiometric quantities of the elements were sealed in a silica tube which heated for 3 days at $950^{\circ} \mathrm{C}$ and then a temperature gradient of $50^{\circ} \mathrm{C}$ between 750 and $800{ }^{\circ} \mathrm{C}$ was established for 15 days. During the slow cooling to room temperature a stop was made at $350^{\circ} \mathrm{C}$. The $\mathrm{X}$-ray diagrams agree with those published in the literature [11]. The resistivity was measured parallel to the layers using a four contacts method at $70 \mathrm{~Hz}$.

The pressure cell used for this work is the high pressure intensifying cell described elsewhere [12]. The actual magnitude of the resistivity has not been measured at room temperature and atmospheric pressure but has been normalized to the value of reference [6].

Our hydrostatic pressure results show a monotonic decrease of the resistivity up to $33 \mathrm{kbar}$, figure 1 , which is not in agreement with the results previously obtained with an anvil technique $[12,13]$. Our results agree with those of the reference [13] for the pressure dependence of the resistivity reported up to $15 \mathrm{kbar}$ at room temperature. However the apparent discrepancy between our hydrostatic pressure data up to $32 \mathrm{kbar}$ and those presented on figure 3 of [13] must be attributed presumably to the use of the Bridgman

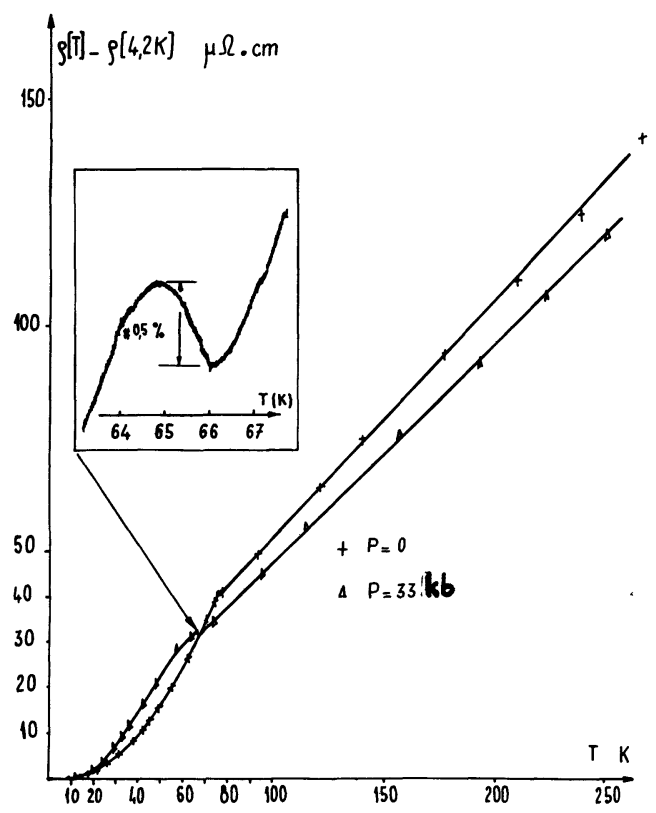

Fig. 1. - Behaviour of the resistivity $\rho(T)-\rho(4.2 \mathrm{~K})$ at 0 and $33 \mathrm{kbar}$. Inset : shape of the resistance anomaly at $T_{\text {CDW }}$ under $33 \mathrm{kbar}$. anvil as the pressure technique. This suggests therefore, that the possible interpolytypic phase transition $2 \mathrm{H} \rightarrow 1 \mathrm{~T}_{1}$ occurs at a pressure higher than $32 \mathrm{kbar}$ at room temperature. However, the most interesting feature of figure 1 comes from the resistance anomaly observed slightly below liquid nitrogen temperature. This anomaly is similar to, although slightly broader than that reported previously in $2 \mathrm{H}-\mathrm{TaS}_{2}$ at $75.3 \mathrm{~K}$ [6]. It is related to the phase transition towards a CDW state. Neither the shape nor the amplitude of the anomaly changes under pressure but a decrease of $T_{\mathrm{CDw}}$ is observed under pressure, figure 2 . The results under pressure indicate a decrease of $T_{\mathrm{CDW}}$ for increasing pressures with a coefficient

$$
\frac{\partial \ln T_{\mathrm{CDW}}}{\partial P}=2.9 \times 10^{-3} \mathrm{kbar}^{-1}
$$

at atmospheric pressure. A stronger pressure dependence is noticed at high pressure. Figure 2 suggests that a critical pressure should be reached above which the undistorted metallic state is stable at low temperature. Our data together with a quartic pressure dependence provide a critical pressure of $43.4 \mathrm{kbar}$. The non zero pressure results were obtained with a sample having a resistivity ratio (room to helium temperature) of 33 whereas the ambient pressure $T_{\mathrm{CDw}}$ has been obtained with a sample of resistivity ratio 10.5. We can see from figure 2 that the results for both samples are in good agreement and therefore it seems that $T_{\text {CDw }}$ in $2 \mathrm{H}-\mathrm{TaS}_{2}$ is not drastically influenced by the resistance ratio. The onset of a CDW corresponds to the occurrence of gaps in some parts of the Fermi surface [14]. Therefore one expects a drop in the number of carriers leading to a rise of the conductivity at $T_{\mathrm{CDw}}$. However the sharpness of the transition suggests a first order transition at $T_{\mathrm{CDW}}$ but in view of the absence of supercooling, it may be only weakly first order, in agreement with the Landau theory analysis of the incommensurate ICDW to normal metal phase transition in layer compounds [14].

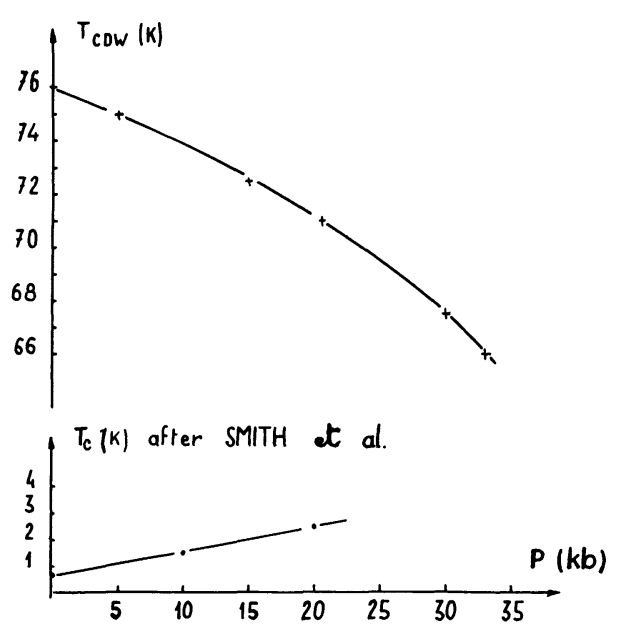

Fig. 2. - Pressure dependence of $T_{\mathrm{CDW}}$ in $2 \mathrm{H}-\mathrm{TaS}_{2}$ up to $33 \mathrm{kbar}$ and pressure dependence of $T_{\mathrm{c}}$ according to Smith et al. [18]. 
The pressure dependence of $T_{\mathrm{CDW}}$ may be understood qualitatively the following way : the ICDW is caused by the divergence of the static dielectric function for a spanning vector $\mathbf{Q}_{0}$ [15]. The vector $\mathbf{Q}_{0}$ connects portions of the Fermi surface with common. tangent planes. The larger the area of nesting, the higher the onset temperature. In 2 dimensional systems, the good nesting is due to the cylindrical shape of the Fermi surface along $\Gamma A$ axis.

Hydrostatic pressure, increasing interlayer coupling will distort the Fermi surface and reduce the nesting, leading to a suppression of the onset temperature.

In the lower part of figure 2, we have plotted the pressure dependence of $T_{\mathrm{c}}$ recently published [16] for $2 \mathrm{H}-\mathrm{TaS}_{2}$. We notice the existence of a strong and positive pressure coefficient

$$
\frac{\partial T_{\mathrm{c}}}{\partial p}=9 \times 10^{-2}\left(\mathrm{~K} \cdot \mathrm{kbar}^{-1}\right)
$$

for a pressure range where our data indicate that the CDW state is stable at low temperature.

Previous high pressure works $[17,18]$ and additional work in progress $\left({ }^{1}\right)$ reveal the same features on $2 \mathrm{H}-\mathrm{NbSe}_{2}$. This gives strength to the argument for the pressure enhanced $T_{\mathrm{c}}$ in layer compounds [19]. Namely, the positive pressure coefficient of $T_{\mathrm{c}}$ is related to the disturbance created on the Fermi surface by the onset of a CDW. In the present work, we see that as pressure increases, $T_{\mathrm{CDw}}$ falls and presumably the gaps at the Fermi surface caused by the CDW become smaller. Therefore, the reduction of $N\left(E_{\mathrm{F}}\right)$ which occurs on cooling through $T_{\mathrm{CDW}}$ becomes weaker under pressure and as a result one can expect an increase of $T_{\mathrm{c}}$.

To summarize : the pressure dependence of $T_{\mathrm{CDW}}$ has been studied up to $33 \mathrm{kbar}$ in $2 \mathrm{H}-\mathrm{TaS}_{2}$. The negative pressure coefficient is probably related to the pressure enhanced interlayer coupling and may suggest a close connection between the existence of a CDW state and a positive pressure dependence of the superconducting transition temperature.

We wish to acknowledge fruitful conversations with J. Friedel and C. Berthier. This work has benefited from the invaluable technical help of G. Malfait.

( $\left.{ }^{1}\right)$ Private communication and preliminary results from Berthier, C.

\section{References}

[1] Wilson, J. A., Di Salvo, F. J. and Mahajan, S., Phys. Rev. Lett. 32 (1974) 882.

[2] Scruby, C. B., Williams, P. M. and Parry,.G. S., Phil. Mag. 31 (1975) 255.

[3] Wilson, J. A., Di Salvo, F. J. and Mahajan, S., Adv. Phys. 24 (1975) 117.

[4] Williams, P. M., Parry, G. S. and Scruby, C. B., Phil. Mag. 29 (1974) 695.

[5] Moncton, D. E., Axe, J. D. and Di Salvo, F. J., Phys. Rev. Lett. 34 (1975) 734.

[6] Tidman, J. P., Singh, O., Curzon, A. E. and Frindt, R. F., Phil. Mag. 30 (1974) 1191.

[7] Chevalier, J. P. A. A. and Stobis, W. M., Phil. Mag. 31 (1975) 733.

[8] Mattheiss, L. F., Phys. Rev. B 8 (1973) 3719.

[9] Jones, R. E., Shanks, H. R., Finnemore, D. K. and MoroSIN, B., Phys. Rev. B 6 (1972) 835.
[10] Flack, H. D., J. Appl. Crystallogr. 5 (1972) 137.

[11] JellineK, F., Less, J., Comm. Metals 4 (1962) 9.

[12] Delaplace, R., Malfait, G. and Jerome, D., to be published in Revue Phys. Appl.

[13] Grant, A. J., Griffiths, T. M., Pitt, G. D. and Yoffe, A. D. J. Phys. C 7 (1974) L 249.

[14] Mc Millan, W. L., preprints 1975.

[15] Chan, S. K. and Heine, V., J. Phys. F 3 (1973) 795.

[16] Smith, T. F., Shelton, R. N. and Schwall, R. E., J. Phys. $F$ 5 (1975) 1713.

[17] Molinie, P., Jerome, D. and Grant, A. J., Phil. Mag. 30 (1974) 1091.

[18] Smith, T. F., Shelton, R. N. and Schwall, R. E., J. Phys. F 4 (1974) 2009.

[19] Friedel, J., J. Physique Lett. 36 (1975) L-279. 